\title{
$\mathcal{A}$ CASE
}

of

\section{INGLINAL ANEURISM,}

CURED AFTER THE USE OF COMPRESSION.

\author{
Br J. A. ALBERS, M.D.
}

OF BREMEN.

Read Jan. 90, 1818.

A SAILOR of the name of Lüder Bölcke, thirtysix years old, who lived in the neighbourhood of Vegesack, came on the 18th of October, 1816, to the surgeon of that place, Mr. Prohfs, in order to consult him concerning a complaint in the right groin. This gentleman found in that situation a strongly pulsating tumor as large as a hen's egg; and declared it immediately to be an aneurism. He advised the patient to go to Bremen, in order to consult Mr. Schmidt, the surgeon, and myself. The patient informed us that he had for a year remarked a swelling as large as a hazel-nut in the right groin, which, however, he took no notice of, as it occasioned him no inconvenience. He did not remember any circumstance which could have been the first cause of this swelling; on the con- 
trary, he asserted, that after great exertion in his labour on board ship, in the month of September, the swelling had attained its present size within four weeks. He had hitherto experienced so little inconvenience from this aneurism, that it required some trouble to dissuade him from making a voyage to the West Indies, which he was then on the point of undertaking. I had been conversing the evening before with my friend, Mr. Schmidt, concerning the numerous operations, which have been performed in England for inguinal aneurism, and proposed that the artery should be tied; the patient, however, positively rejectea this proposal, so that nothing remained for us but to try compression. For this purpose we gave him a compressorium, which, like the old rupture-bandages, consisted of a cushion fastened to a strap, which was buckled round the body. On the lower and inner side of the cushion there was also a strap, which was fastened round the thigh by means of a buckle. The cushion itself consisted of two iron pieces : the uppermost had the form of a common cushion, and was externally covered with leather: the lower piece was round, and covered below with strong cloth, and above with leather. It was connected with the upper piece by a screw, by the operation of which its pressure on the tumor could be increased or diminished at pleasure.

As the patient resided near twelve miles from Bremen, we heard nothing more from him at that 
time; and what I now relate has been since com. municated to me by Mr. Prohfs in Vegesack, and by the patient himself, whom I saw there in the end of the month of September in this year.

After be had borne the compression constantly for two months, he felt such 2 violent pain in the aneurism, and had such a considerable cedematous swelling in the thigh and leg, that he was forced to take off the instrument. Nevertheless the violence of the pain continued so as to confine him to bed.

During this period, the swelling attained its greatest extent; it had a red and inflamed appearance, and was fully as large as a goose's egg; the pulsation was also now the strongest. The whole of the thigh was extremely painful, and a distressing coldness was experienced in that part, on which account it was often rubbed with flannel. During this period, he observed a low diet, and his treatment by Mr. Prohfs was antiphlogistic, but without the loss of blood.

After he had remained a week quietly in bed, the pain decreased, and the pulsation in the swelling lessened. He now put on the compressorium again, without experiencing much inconvenience from it; he still continued in bed. The size of the aneurism now decreased, the swelling of the thigh and the pain therein became less and less, so 
that the patient was enabled again to go with the help of 2 stick. The amendment was now uninterrupted, until the month of June, 1817 , when no further pulsation could be perceived in the inguinal region. The swelling of the thigh and the pains in it had also disappeared totally. The compressorium was now no longer used.

When I saw the patient in the end of September, I could not detect the slightest pulsation in the inguinal region. I conclude that the femoral artery must have been obliterated. The whole thigh was rather thin, and a little cedematous swelling was still to be perceived. When the patient walks much, he feels still a weariness in the whole of the leg; in other respects he finds himself so well, that he intends soon to serve again as a sailor.

It is hardly necessary to add, that I do not communicate this case in order to depreciate the use of the ligature in inguinal aneurism. The operation has been performed, not only by many English, but also by some American surgeons, with such decisive and favourable results, that compression cannot be put in competition with it, as Mr. Hodgson*, in his classical work, and Mr. Traverst, in his instructive paper, have clearly shewn.

- A Treatise on the Diseases of Arteries and Veins, containing the Pathology and Treatment of Aneurisms and wounded Arteries. London, 1815.

† Medico-Chururgical Transactions, Vol. VI. p. 632 et seq. 
Some fortunate cases, however, particularly of femoral and inguinal aneurisms, shew us that compression is not to be entirely rejected, particularly as patients are sometimes met with, who will not submit to the operation.

It remains to be inquired, whether the compression effected the cure in this case, or whether it ought to be considered as an example of spontaneous recovery? since here, as in the cases of spontaneous cure mentioned by Mr. Crampton*, an augmentation of bulk took place, in consequence of the aneurismal coverings having been attacked by inflammation, before the swelling began to subside.

For a merchant of this place, now deceased, who suffered by an aneurism of the brachial artery, and who would not submit to the ligature, I could effect no cure, notwithstanding compression was continued for six years; but the aneurism did not augment in size during its application. This patient, who had long suffered under angina pectoris, died suddenly at dinner without the smallest preceding attack of suffocation.

* Medico-Chirurgical Transactions, Vol. VII. Part ii. p. 341 et seq. 